\title{
The relationship between general and emotional intelligence in preschool children
}

\author{
Elnara I. Izmaylova ${ }^{1}$, Tatyana L. Kuzmishina ${ }^{1 *}$, Maria Aleksandrovna Gorelkina ${ }^{1}$, Elena $N$. \\ Korneva $^{1}$, and Anastasiia Vladimirovna Lukinova ${ }^{1}$ \\ ${ }^{1}$ Moscow Pedagogical State University (MPGU), Faculty of Pedagogy and Psychology, Department \\ of Psychology of Education, Moscow, Russia
}

\begin{abstract}
This paper examines the relationship between general intelligence and emotional intelligence in preschool children older than five years and the main areas of research on general and emotional intelligence. Currently, a high level of general and emotional intelligence is viewed as a condition for achieving success both in one's profession and in life in general. The relevance of this study is conditioned by the need to study general intelligence and emotional intelligence to improve the intellectual and emotional life of people, which in turn contributes to the solution of both individual and social problems. This study aims to review the levels of general and emotional intelligence formation in preschool children older than five years. The paper contains a retrospective analysis of the problem of studying emotional and general intelligence in Russian and foreign psychology. Various approaches to the study of general and emotional intelligence are analyzed. Based on a review of the literature on the topic of the study, the prerequisites for the emergence of the concept of emotional intelligence are outlined. The content of such concepts as "intelligence" and "emotional intelligence" is outlined, with a brief excursion into the history of the emergence and spread of these concepts. The paper also contains terms analogous to the concept of emotional intelligence and describes in detail the structural components of emotional intelligence within the framework of various models. Empirically, the levels of general and emotional intelligence of preschool children older than five years have been identified. A comparative correlation study of the levels of emotional and general intelligence of preschool children was carried out. The authors present the results of an experimental study on the absence of interdependence of general and emotional intelligence in preschool children older than five years.
\end{abstract}

Keywords: intelligence, general intelligence, emotional intelligence, development of preschool children.

\section{Introduction}

At the present stage, the study of general and emotional intelligence continues. Emotional intelligence is a poorly studied phenomenon in comparison with general intelligence, but,

\footnotetext{
*Corresponding author: tl.kuzmishina@mpgu.su
} 
according to D. Goleman, no less important [1]. D. Goleman includes such abilities as awareness of emotions, control over emotions, motivation, empathy, and management of social relationships in emotional intelligence [1]. The concept of intelligence is understood as the ability to act rationally (D. Wechsler [2]), to use thinking to achieve a goal (W. Stern [3]), etc.

The problems of emotional intelligence were studied by such foreign scientists as R. BarOn, P. Salovey, D.R. Caruso [4], D. Goleman [1]. In Russian psychology, emotional intelligence was studied by I.N. Andreeva [5], D.V. Lyusin [6], and others.

To date, theories of intelligence have been developed by H. Gardner, M. Anderson [7], S. Ceci [8], and others. Among Russian scientists, the problems of intelligence have been studied by L.S. Vygotsky, B.M. Velichkovsky, E.I. Stepanova and others [9, 10].

In our study, we carried out diagnostics of the general and emotional intelligence of preschool children older than five years using the "Emotional faces" method developed by N.Ya. Semago and the Wechsler test designed for children from 4 to 6.5 years. The object of our study is the relationship between general and emotional intelligence. Our study aims to review the levels of formation of general and emotional intelligence in preschool children older than five years.

There are many directions in the study of intelligence, each of which opens up new aspects of the nature of intelligence. F. Galton, H. Spencer, K. Pearson were the first researchers to study intelligence. They studied intelligence from a genetic point of view. Then the concept of "mass brain activity" appeared, which, according to K.S. Lashley was identified with intellectual ability. Then, C. Spearman concluded the existence of unifying intellectual abilities, on which the success of any intellectual activities and special abilities necessary for a specific activity depended. Then, A. Binet's intelligence test was created, which considered intelligence as a set of mental abilities. A.Binet's view of intelligence was consistent with the results of the study by L. Thurstone, who proposed a multivariate model of intelligence. Seven of those factors were mentioned most frequently in his research, namely verbal comprehension (V), spatial factor $(\mathrm{S})$, numerical factor $(\mathrm{N})$, speech fluency (W), speed of perception (P), associative memory (M). Later, an alternative theory of J. Guildford appeared, which was based on the following scheme: stimulus (content) - latent operation (mental processes) - reaction (the result of the operation).

J. Piaget defines intelligence as the perfect form of adaptation of the organism to the environment. According to the genetic approach, intelligence adapts to reality. Its function is to organize and structure the interaction of the individual with the outside world.

According to the informational approach of $\mathrm{H}$. Eysenck, the structure of intelligence consists of psychometric, social, and biological levels. Biological intelligence includes the specifics of the functioning of brain structures involved in cognitive activity. Psychometric intelligence is measured by intelligence tests. He defines the ability to use psychometric intelligence to adapt to social norms as social intelligence [7].

According to R. Sternberg's model of intelligence, meta-components (information processing management processes), executive components (processes of a lower hierarchy level), and knowledge-acquisition components (selective comparison, combination, coding) are responsible for information processing [11]. R. Sternberg's model includes in the structure of intelligence such factors as control of information and the use of strategies for solving problems [12].

The history of the emergence of the concept of emotional intelligence begins with the fact that in 1940 D. Wechsler drew attention to the existence of non-intellectual factors in intelligence. R.V. Leaper noted that emotions contributed to the maintenance of activity and were part of the so-called "logical thoughts."

For the first time, an analog of the concept of emotional intelligence called "emotional coefficient" was introduced by R. Bar-On in 1985. A year later, a publication by V.L. Payne 
appeared, describing the forms of intelligence, in particular the emotional form of intelligence.

In 1990, P. Salovey and J. Mayer introduced the term "emotional intelligence" into scientific circulation [4]. They saw emotional intelligence as the ability to track and distinguish between one's own and others' emotions, to use the information received in one's activities, and the ability to express emotions [13].

The term "emotional intelligence" was popularized in 1995 by D. Goleman [1]. He defines emotional intelligence as a set of abilities, with the help of which an individual recognizes the feelings of others, shows empathy, controls their emotional state, and motivates themselves to achieve their goals. He added social skills, persistence, and enthusiasm to the components of emotional intelligence [14].

R. Bar-On defines emotional intelligence as a set of non-cognitive abilities that help a person to cope with life situations, and in 1997 he created the scale of the coefficient of emotional intelligence. He distinguishes five spheres of emotional abilities: interpersonal, intrapersonal, stress resistance sphere, adaptability, and general mood [5].

In 2004, D.V. Lyusin published his first paper on emotional intelligence [6]. He defined emotional intelligence as a psychological formation that was formed during life under the influence of ideas about emotions (as values), cognitive ability (processing information related to the emotional sphere), and the characteristics of one's emotionality.

In 2004 A.I. Savenkov included emotional intelligence in the social intelligence and added new criteria that had not been noted by his predecessors, namely social perception and social memory, and the suggestive capabilities of the individual [15].

\section{Methods}

The study involved preschool children attending a kindergarten in Moscow. In total, 30 children aged 5-6 years were examined. The level of emotional intelligence was determined using the "Emotional faces" method by N. Y. Semago, designed for children from 3 to 12 years and including two series of images of emotional facial expression. This technique allows assessing the ability to recognize emotional states in children. The procedure for conducting this study took place in three stages. The first stage involved examining the ability to recognize emotions using schematic images. At the second stage, real images were presented for this purpose. At the third stage, the children were asked to come up with a story based on two selected images.

The level of general intelligence was determined using the children's version of the Wechsler test designed for preschool children from 4 to 6.5 years, which is used to study the intellectual abilities of children. This technique allows assessing general, verbal, and nonverbal intelligence. The methodology consists of ten subtests, which add up to an overall IQ.

\section{Results and discussion}

As a result of the study, it was found that in subjects with high emotional intelligence, the level of general intelligence was higher than average in $22 \%$ of cases, $33 \%$ of the subjects had a reduced norm of general intelligence, and an average level of general intelligence was observed in $45 \%$ of cases. In subjects with low emotional intelligence, $50 \%$ had a high level of general intelligence and the other $50 \%$ had a reduced norm of general intelligence. Subjects with an average level of emotional intelligence had a high level of general intelligence in $7 \%$, a level of general intelligence above the average in $57 \%$, an average level of general intelligence in $29 \%$, and a low level of general intelligence in $7 \%$ of cases. 
With a high indicator of the level of general intelligence, the average emotional intelligence was observed in $50 \%$ of the subjects, and the other $50 \%$ had low emotional intelligence. With a level of general intelligence above average, high emotional intelligence was found in $20 \%$ of the subjects, and average emotional intelligence was found in $80 \%$ of the subjects. With an average level of general intelligence, $50 \%$ of the subjects had high emotional intelligence and $50 \%$ of the subjects had an average level of emotional intelligence. In the group with a reduced rate of general intelligence, high emotional intelligence was observed in $75 \%$ and low in $25 \%$ of the subjects. In the group with a low level of general intelligence, $100 \%$ had an average level of emotional intelligence.

As a result of the correlation analysis, it was found that there was no correlation between emotional intelligence and general intelligence. Pearson's correlation coefficient $r=0.012894127$, i.e. emotional intelligence is not correlated with general intelligence.

\section{Conclusion}

Thus, intelligence is a set of abilities that are necessary for the adaptation of an individual to the world around them. Emotional intelligence is the cognitive ability to recognize and understand both one's own emotions and the emotions of other people, as well as to manage emotions and empathy.

As a result of the study, it was demonstrated that there was no correlation between the levels of emotional and general intelligence. Based on the Pearson correlation coefficient, $r=0.012894127$, it can be stated that the strength of the correlation between the indicators of emotional and general intelligence is very weak.

Due to the lack of correlation between emotional and general intelligence, it is necessary to conduct further research on the relationship between emotional intelligence and personality traits, as personality traits can influence an individual's emotional response and ability to emotionally regulate. The study of emotional intelligence can be continued in the framework of the dispositional model of personality, in particular, using the five-factor model. It is also necessary to analyze the relationship between emotional intelligence and personality traits in the context of culture as culture can also influence the characteristics of the expression of emotions, determine regulation, as well as the specifics of emotional experiences.

\section{References}

1. D. Goleman, Emotional intelligence: Why it can matter more than IQ (Alpina, Moscow, 2017)

2. D. Wechsler, The measurement of adult intelligence (Kessinger Publishing, Whitefish, Montana, 2007)

3. W. Stern, Psychology of early childhood: up to the sixth year of age (Routledge, London, 2017)

4. J.D. Mayer, P. Salovey, What is emotional intelligence?, in P. Salovey, D. Sluyter (Eds.). Emotional development and EI: Educational implications, 3-34 (Basic Books, New York, 1997)

5. I. N. Andreeva, Emotsionalnyi intellekt kak fenomen sovremennoi psikhologii [Emotional intelligence as a phenomenon of modern psychology] (PGU, Novopolotsk, 2011)

6. D.V. Lyusin, A.-R. Mohammed, Psychology. Journal of the Higher School of Economics, 17(2), 315-327 (2020) 
7. M. N. Anderson, Vestnik Leningradskogo Gosudarstvennogo Universiteta imeni A.S. Pushkina, 2, 204-210 (2016)

8. S.J. Ceci, On intelligence. More or less: A bio-ecological treatise on intellectual development (Prentice Hall, Hoboken, NJ, 1990)

9. A. Yasnitsky, Sergei Rubinstein as the founder of Soviet Marxist psychology: "Problems of Psychology in the Works of Karl Marx" (1934) and beyond, in A. Yasnitsky (Ed.), A History of Marxist Psychology: The Golden Age of Soviet Science, 58-91 (Routledge, London, New York, 2021)

10. O. A. Tokareva, A. V. Seryi, M. S. Yanitskii, Siberian Journal of Psychology, 77, 153$175(2020)$

11. R.J. Sternberg, American Scientist, 74 (2), 137-143 (1986)

12. J. Gottman, Emotsionalnyi intellekt rebenka. Prakticheskoe rukovodstvo dlya roditelei [Raising an emotionally intelligent child. The heart of parenting] (Mann, Ivanov i Ferber, Moscow, 2018)

13. Yu. V. Bratchikova, N.S. Voloshina, Pedagogicheskoe obrazovanie v Rossii, 7, 30-37, (2019)

14. A. S. Anokhina, O. A. Tokareva, Problemy sovremennogo pedagogicheskogo obrazovaniya, 58(2), 311-314 (2018)

15. A.I. Savenkov, Psychology. Journal of the Higher School of Economics, 2(4), 94-101 (2005) 